\title{
Game Edukasi Pengenalan Objek Untuk Anak Usia 6-8 Tahun
}

\author{
Rekayanti \\ Politeknik Pertanian Negeri \\ Samarinda \\ Teknologi Rekayasa Perangkat \\ Lunak Manajemen Pertanian \\ Samarinda, Indonesia \\ yreka26@gmail.com
}

\author{
Nisa Rizqiya Fadhliana \\ Politeknik Pertanian Negeri \\ Samarinda \\ Teknologi Rekayasa Perangkat \\ Lunak Manajemen Pertanian \\ Samarinda, Indonesia \\ nisafadhliana@gmail.com
}

\author{
Dwi Arief Prambudi \\ Politeknik Pertanian Negeri \\ Samarinda \\ Teknologi Rekayasa Perangkat \\ Lunak Manajemen Pertanian \\ Samarinda, Indonesia \\ prambudiariefdwi@gmail.com
}

\begin{abstract}
Abstrak - Penelitian ini dilatarbelakangi oleh Pesatnya perkembangan teknologi saat ini juga sangat mempengaruhi dunia pendidikan dimana cara belajar mengajar tidak lagi mengharuskan murid dan pengajar harus bertemu secara langsung. Selain itu saat ini peran orang tua sangatlah diharapkan, terutama jika menyangkut permainan menggunakan media elektronik seperti handphone, laptop maupun komputer. Selain itu salah satu alasan pemilihan judul penelitian ini di karenakan karakter anak yang pada umumnya lebih menyukai konsep belajar sambil bermain yang dianggap lebih menarik dan menyenangkan. Aplikasi ini dibuat dengan adobe flash cs5 dan menggunakan bahasa pemrograman action script 2. Adapun metode pengujian aplikasi dilakukan dengan menyebarkan kuisioner ke 40 siswa yang terbagi di dua sekolah yaitu 10 siswa di Sekolah Dasar Negeri 007 dan 30 siswa di Sekolah Dasar Negeri 008 Samarinda Seberang. Maka berdasarkan latar belakang tersebut dibuat aplikasi game edukasi pengenalan objek, sehingga anak-anak dapat belajar sambil bermain. Aplikasi ini diperuntukkan untuk anak usia 6 sampai 8 tahun.
\end{abstract}

Kata kunci - game, pengenalan objek, sekolah dasar, edukasi, adobe flash

\section{PENDAHULUAN}

Setiap orang tua pastinya menginginkan pendidikan yang terbaik untuk anak-anaknya, salah satu cara yang dilakukan adalah dengan memasukkan anak sekolah pada usia dini, mengikut sertakan anak dalam les maupun latihan sedini mungkin serta memilih metode pengajaran menggunakan game edukasi. Pesatnya perkembangan teknologi saat ini juga sangat mempengaruhi dunia pendidikan dimana cara belajar mengajar tidak lagi mengharuskan murid dan pengajar harus bertemu secara langsung. Selain itu saat ini peran orang tua sangatlah diharapkan, terutama jika menyangkut permainan menggunakan media elektronik seperti handphone, laptop maupun komputer.

Karakter dasar anak yang lebih suka bermain sambil belajar juga merupakan salah satu pertimbangan penelitian ini. Selain senang bermain anak juga cenderung sulit untuk fokus belajar sehingga dengan adanya aplikasi ini maka diharapkan anak dapat belajar sambil bermain dan dapat lebih fokus karena konten yang dianggap menarik.

Game edukasi merupakan permainan yang dikemas untuk merangsang daya pikir termasuk meningkatkan konsentrasi dan memecahkan masalah. Teknik pembelajaran interaktif yang efektif bagi anak usia dini adalah dengan menggunakan game edukasi, hal ini dikarenakan sebagian besar anak di usia dini memiliki rasa ingin tahu yang tinggi terhadap semua yang berada di lingkungan sekitarnya (Eva, 2009). Salah satunya adalah game yang coba dibuat oleh peneliti yaitu game pengenalan objek untuk anak usia 6-8 tahun. Pada penelitian kali ini akan memfokuskan untuk membantu anak mengenal objek pada tiga kategori yaitu pengenalan anggota tubuh, pengenalan alat tulis, dan pengenalan bentuk objek.

Berdasarkan latar belakang diatas dapat dirumuskan masalah yaitu bagaimana cara merancang suatu permainan yang dapat digunakan oleh anak sebagai salah satu media pembelajaran yang mudah dan menarik menggunakan adobe flash.

Adapun tujuan yang ingin dicapai dalam pembuatan aplikasi ini adalah membantu anak dalam mengenal objek yang ada dalam permainan, selain itu permainan ini juga untuk membantu orang tua dan guru dalam memanfaatkan teknologi sebagai media pembelajaran sehingga anak menjadi lebih semangat dalam belajar.

\section{TINJAUAN PUSTAKA}

\section{A. Kajian Ilmiah}

Beberapa penelitian yang digunakan sebagai pedoman dan acuan dalam Skripsi ini antara lain:

1. Penelitian yang dilakukan oleh Novitasari (2010) dengan judul Pembangunan Media Pembelajaran Bahasa Inggris Untuk Siswa Kelas 1 Pada Sekolah Dasar Negeri 15 Sragen.

2. Penelitian yang dilakukan oleh Dewi (2012) dengan judul Pengembangan Game Pengenalan Hewan Dalam Bahasa Inggris Sebagai Media Pembelajaran Siswa SD Berbasis Macromedia Flash.

3. Penelitian yang dilakukan oleh Cahyawan dan Buana (2014) dengan judul Aplikasi Game Edukasi Trash Grabber.

4. Penelitian yang dilakukan oleh setyawan (2015) dengan judul Aplikasi Mengenal Abjad A-Z. 
Adapun table studi literatur dapat dilihat pada table dibawah ini.

Tabel 1. Studi Literatur

\begin{tabular}{|c|c|c|}
\hline No & Nama & Judul \\
\hline 1 & $\begin{array}{c}\text { Denny } \\
\text { Riska } \\
\text { Permatasari }\end{array}$ & $\begin{array}{lr}\text { Pembangunan } & \text { Media } \\
\text { Pembelajaran } & \text { Bahasa } \\
\text { Inggris Untuk } & \text { Siswa } \\
\text { Kelas 1 Pada } & \text { Sekolah } \\
\text { Dasar Negeri 15 Sragen }\end{array}$ \\
\hline 2 & $\begin{array}{l}\text { Ghea Putri } \\
\text { Fatma Dewi }\end{array}$ & $\begin{array}{lr}\text { Pengembangan } & \text { game } \\
\text { Pengenalan } & \text { Hewan } \\
\text { Dalam Bahasa } & \text { Inggris } \\
\text { Sebagai } & \text { Media } \\
\text { Pembelajaran Siswa SD } \\
\text { Berbasis Macromedia } \\
\text { Flash }\end{array}$ \\
\hline 3 & $\begin{array}{l}\text { I Dewa Putu } \\
\text { Agus, A.A. } \\
\text { Kt Agung } \\
\text { Cahyawan } \\
\text { dan Putu } \\
\text { Wira Buana }\end{array}$ & $\begin{array}{lr}\text { Aplikasi Game } & \text { Edukasi } \\
\text { Trash Grabber } & \text { Untuk } \\
\text { Mengenal } & \text { Jenis-Jenis } \\
\text { Sampah } & \text { Pada } \\
\text { Smartphone } & \text { Berbasis } \\
\text { Android } & \\
\end{array}$ \\
\hline 4 & $\begin{array}{c}\text { David } \\
\text { setyawan }\end{array}$ & $\begin{array}{l}\text { Aplikasi Mengenal Abjad } \\
\text { A-Z }\end{array}$ \\
\hline
\end{tabular}

\section{B. Media Pembelajaran}

Beberapa makna atau pengertian tentang media pembelajaran yang disampaikan oleh para ahli, dapat dirangkum bahwa media pembelajaran adalah segala sesuatu yang menyangkut software dan hardware yang dapat digunakan untuk menyampaikan isi materi ajar dari sumber pelajar (individu atau kelompok), yang dapat merangsang pikiran, perasaan, perhatian dari minat pelajar sedemikian rupa sehingga proses belajar baik di dalam maupun di luar kelas menjadi lebih efektif.

Perubahan dan kemajuan teknologi komunikasi dan informasi pada saat ini, media pembelajaran memiliki posisi sentral dalam proses belajar dan bukan semata-mata sebagai alat bantu. Media adalah bagian integral dari proses belajar mengajar. Dalam posisi seperti ini, penggunaan media pembelajaran dikaitkan dengan apa saja yang dapat dilakukan oleh media, yang mungkin tidak mampu dilakukan oleh guru (atau guru melakukannya kurang efifsien).

\section{Multimedia}

Multimedia terdiri dari dua kata yaitu multi dan media. Multi artinya bisa lebih dari satu sedangkan media merupakan sarana untuk menampilkan atau mendistribusikan informasi dalam bentuk teks, gambar, suara, musik, dan lain-lain. Jika digabungkan kedua kata tersebut dapat diartikan secara harfiah, multimedia adalah kombinasi berbagai sarana baik berupa teks, gambar, suara, animasi maupun video untuk menampilkan atau sebagai medium untuk mendistribusikan informasi dalam berbagai bentuk melalui peralatan digital. Peralatan digital yang ada meliputi komputer, tablet, smartphone, dan PDA.

\section{Game Edukasi}

Game merupakan kata yang berasal dari bahasa inggris yang berarti permainan. Game atau permainan adalah sesuatu yang dapat dimainkan dengan aturan tertentu sehingga ada yang menang dan ada yang kalah, biasanya dalam konteks tidak serius atau dengan tujuan refreshing. (Dawang Muchtar,2005). Menurut Kamus Besar Bahasa Indonesia (KKBI), pengertian edukasi adalah pedidikan. Dan menurut UNESCO dalam bukunya yang berjudul Dasar Konsep Pendidikan Moral di sebutkan bahwa "education is now engaged is preparinment for a tife society which does not yet exist" atau bahwa pendidikan itu sekarang adalah untuk mempersiapkan manusia bagi suatu tipe masyarakat yang masih belum ada. Konsep system pendidikan mungkin saja berubah sesuai dengan perkembangan masyarakat dan pengalihan nilai-nilai kebudayaan (transfer of culture value)..

Berdasarkan uraian dari pengertian kedua kata yaitu game dan edukasi maka dapat disimpulkan bahwa seiring dengan berkembangnya teknologi termasuk game dan edukasi, kini keduanya telah dapat di gunakan sebagai sarana pendidikan. Game edukasi adalah permainan yang dirancang atau dibuat untuk merangsang daya pikir termasuk meningkatkan konsentrasi dan memecahkan masalah (Handriyantini, 2009).

\section{E. Game Pengenalan}

Pada penelitian kali ini akan membahas tentang pengembangan game pengenalan, dimana sesuai dengan namanya game ini biasanya dikembangkan untuk anak usia dini maupun anak-anak usia sekolah dasar. Saat ini ada banyak kategori game yang telah dikembangkan. Kategori paling umum yang banyak tersedia saat ini beberapa diantaranya adalah pengenalan angka, huruf, hewan dan buah. Game ini tidak hanya dimainkan untuk hiburan di rumah karena saat ini sudah banyak guru yang menggunakan game edukasi baik untuk game pengenalan maupun game untuk belajar berhitung dan membaca atau mengeja.

\section{F. Adobe Flash}

Flash adalah salah satu software animasi yang dikeluarkan Macromedia yang kini telah diadopsi oleh Adobe, Inc . Adobe Flash Professional CS6 merupakan versi Adobe Flash yang telah diperbarui dari versi sebelumnya yaitu Adobe Flash CS3 Professional, Adobe Flash CS4 Professional, dan Adobe Flash Professional CS5. Adobe Flash Professional CS6 adalah software grafis animasi yang dapat membuat objek grafis dan menganimasikannya sehingga kita dapat langsung membuat objek desain tanpa harus menggunakan software grafis 24 pendukung seperti Ilustrator atau Photoshop (Island Script, 2008)

\section{METODE PENELITIAN}

\section{A. Waktu dan Tempat}

Penelitian ini dilakukan di 2 sekolah dasar yang ada di Samarinda Seberang yaitu SDN 007 dan SDN 008. Waktu 
penelitian dilakukan pada Semester genap ajaran 20182019 dilaksanakan selama periode waktu kurang lebih 11 (sebelas) bulan, terhitung dari bulan Oktober 2018 September 2019 yang meliputi pembuatan proposal, pengambilan data, pembuatan aplikasi, pengujian aplikasi dan penyusunan laporan.

\section{B. Alat dan Bahan}

Pengembangan aplikasi game edukasi ini menggunakan satu unit laptop dengan spesifikasi sebagai berikut:

1. Spesifikasi hardware yang digunakan dalam pengembangan aplikasi ini adalah sebagai berikut:

a. Laptop Lenovo G40-30

b. INTEL $®$ Celeron ${ }^{\circledR}$ N2840 Processor $(2.16 \mathrm{GHz}$ , $1 \mathrm{M}$ cache)

c. RAM $2 \mathrm{~GB}$

d. Windows 8

2. Spesifikasi software yang digunakan adalah sebagai berikut:
a. Adobe Flash

b. Paint 3D

\section{Prosedur Penelitian}

Berikut ini merupakan penjelasan mengenai langkahlangkah metode penelitian yang ada pada gambar. Adapun langkah-langkah metode penelitian dapat dilihat pada gambar yang ada dibawah uraian.

a. Pemilihan Judul

Langkah awal yang dilakukan saat akan melakukan penelitian adalah menentukan judul yang akan digunakan sebagai dasar penelitian. Tahap ini dilakukan agar penelitian dapat dilakukan terfokus pada judul yang telah ditentukan.

b. Penyusunan Proposal

Pada tahap ini dilakukan penyusunan proposal sebagai langkah lanjutan dari judul yang telah dipilih. Pada tahap ini akan menjelaskan semua hal yang berkaitan dengan langkah awal penelitian.

c. Pembuatan Flowchart

Pembuatan flowchart dilakukan untuk menentukan langkah-langkah atau metode yang akan dilakukan selama proses penelitian berlangsung

d. Pembuatan Storyboard

Storyboard secara umum menggambarkan alur dari sebuah cerita atau gambaran dari suatu projek yang akan dikerjakan.

e. Pembuatan Aplikasi

Pada tahap ini penelitian telah memasuki tahap pembuatan aplikasi dimana aplikasi akan diselesaikan pengerjaannya agar dapat digunakan sesuai dengan tujuan pembuatan aplikasi itu sendiri.

f. Pengujian Aplikasi

Setelah pembuatan aplikasi maka hal yang tidak kalah penting adalah pengujian aplikasi untuk mengetahui apakah aplikasi dapat digunakan atau tidak. Jika aplikasi belum berhasil maka harus dilakukan perbaikan aplikasi. Namun jika aplikasi berhasil maka aplikasi dapat digunakan.

\section{g. Menampilkan Hasil}

Tahap akhir dari penelitian ini adalah saat aplikasi yang telah dikembangkan siap untuk di presentasikan dan menampilkan hasil dari pengembangan aplikasi.

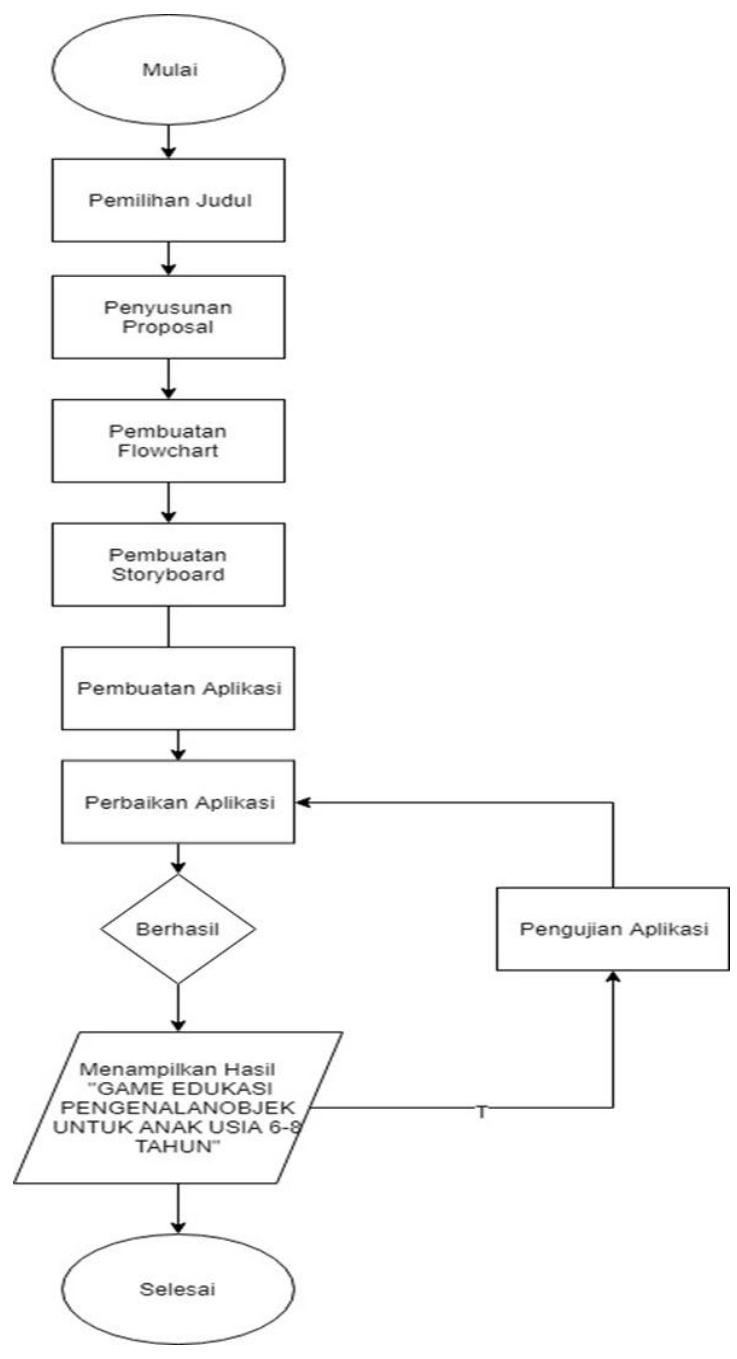

Gambar 1. Prosedur Penelitian

\section{HASIL DAN PEMBAHASAN}

Berikut ini merupakan hasil dari game edukasi pengenalan objek untuk anak usia 6-8 tahun. Tampilan dari aplikasi dibuat sesederhana mungkin dengan fitur yang diperlukan agar memudahkan anak dalam menggunakan aplikasi 


\section{Halaman Menu Utama}

Menu utama merupakan halaman yang berisi beberapa menu yaitu Menu Jenis game, Menu Info serta Menu Petunjuk. Menu Jenis Game digunakan untuk memilih jenis permainan yang ingin dimainkan. Sedangkan pada Menu Petunjuk berisi tentang arahan atau petunjuk cara memainkan game. Dan pada Menu Info terdapat biodata singkat pembuat game. Desain dapat dilihat pada gambar 2 .

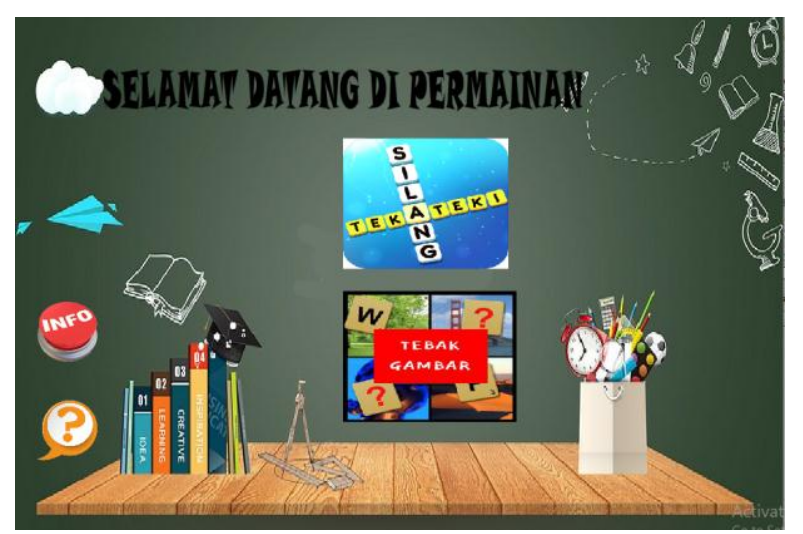

Gambar 2. Halaman Utama

\section{Halaman Kategori}

Halaman kategori merupakan halaman yang berisikan kategori dari game dimana terdapat Menu Alat Tulis, Bangun Ruang/Bangun Datar, dan Menu Home. Ketika memilih kategori yang diinginkan maka apliksi akan menampilkan game sesuai dengan kategori yang dipilih. Menu Home berfungsi untuk menampilkan Menu Utama ketika di pilih oleh pemain. Desain dapat dilihat pada gambar 3.

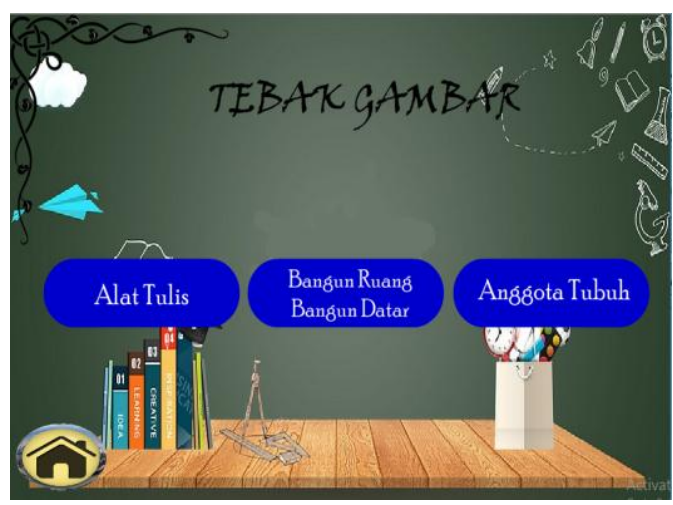

Gambar 3. Halaman Kategori

\section{Halaman Soal Tebak Gambar}

Halaman soal tebak gambar merupakan halaman yang berisi tampilan nama objek yang harus di tebak oleh pemain dengan cara menebak gambar yang dimaksud oleh teks yang ada pada bagian atas tampilan. Desain dapat dilihat pada gambar 4



Gambar 4. Halaman Soal Tebak Gambar

4. Halaman Soal Teka-Teki Silang

Halaman soal merupakan halaman yang berisi tampilan soal dari jenis permainan teka-teki silang. Desain dapat dilihat pada Gambar 5.

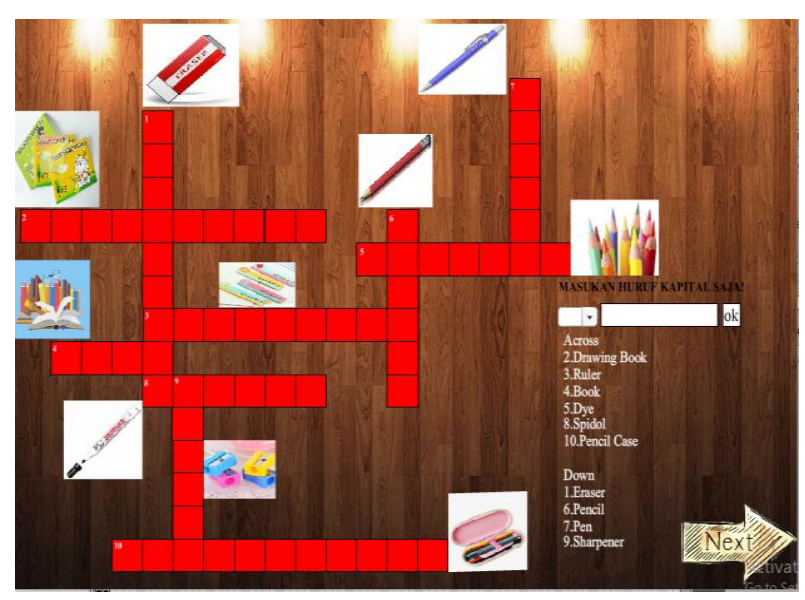

Gambar 5. Halaman Teka-Teki Silang

5. Halaman Pop-Up

Pada tampilan pop-up terdapat tombol reload (main lagi) dan tombol home (halaman awal). Desain dapat dilihat pada gambar dibawah ini:

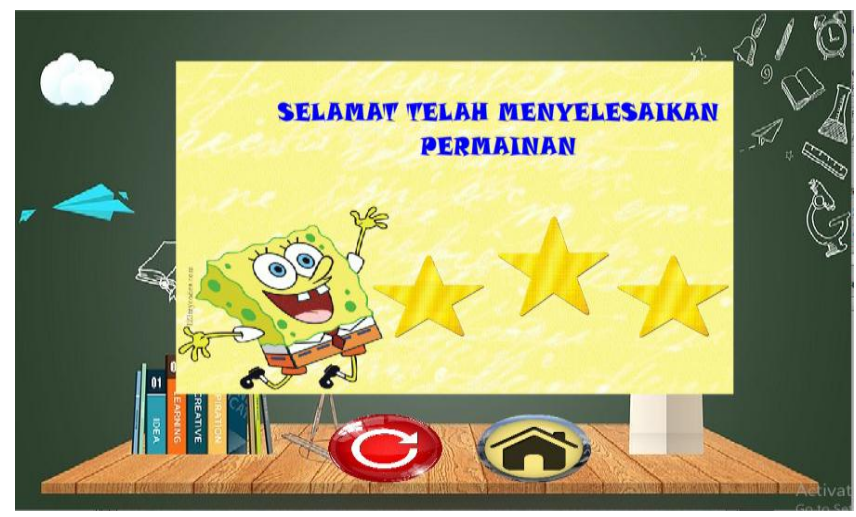

Gambar 6. Halaman Pop-up 
6. Halaman Petunjuk

Pada halaman petunjuk selain berisi petunjuk permainan pada halaman ini juga terdapat tombol home (halaman awal) untuk kembali ke menu utama.

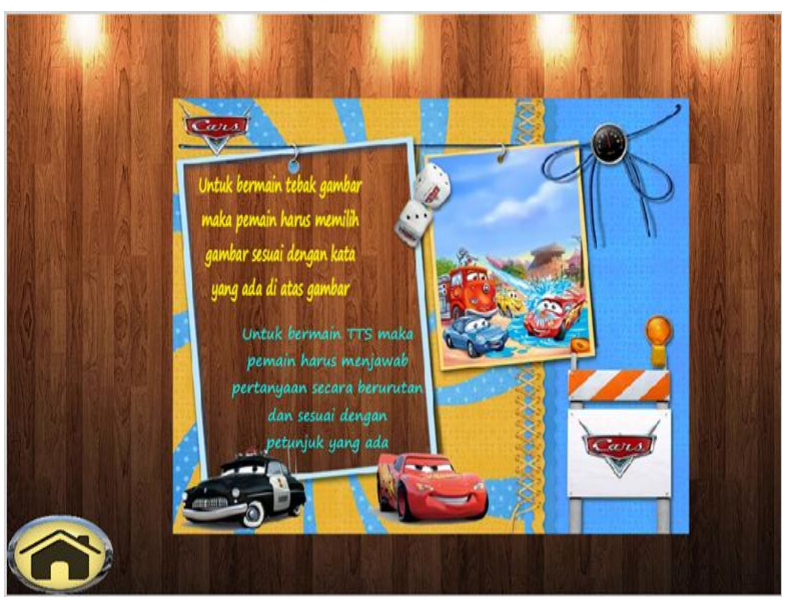

Gambar 7. Halaman Petunjuk

7. Halaman Tentang Pada halaman tentang terdapat informasi biodata singkat peneliti dan tombol home untuk kembali ke halaman utama

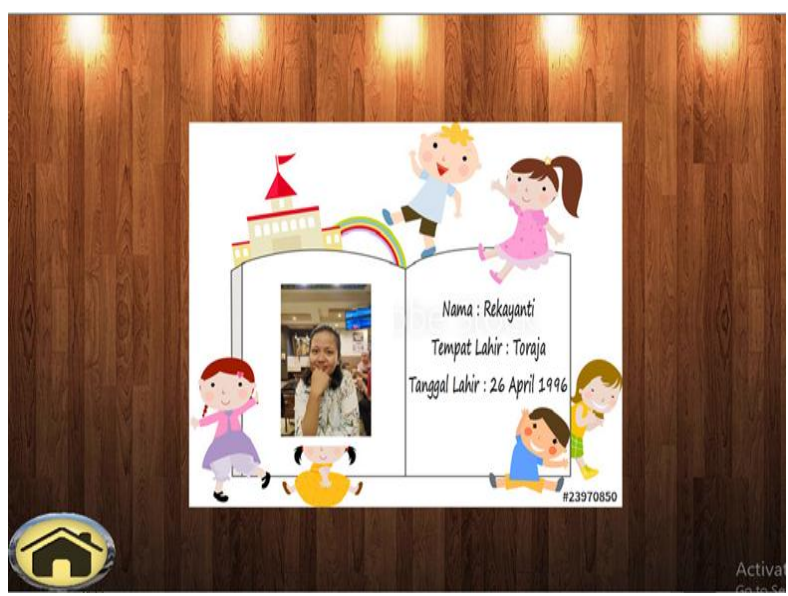

Gambar 8. Halaman Tentang

\section{KESIMPULAN}

Berdasarkan hasil penelitian dan pembahasan maka kesimpulan yang dapat diambil dari penelitian ini adalah Aplikasi pengenalan objek ini dibuat dengan adobe flash cs 5 menggunakan action script 2 dan bertujuan untuk membantu anak mengenal objek berdasarkan dengan ketiga kategori yang ada di permainan. Serta membantu orang tua dan guru dalam memanfaatkan perkembangan teknologi untuk menarik minat murid dalam mempelajari mengenai nama-nama objek.

Berdasarkan dari hasil penelitian ini penulis menyadari bahwa selama pengembangan aplikasi ini terdapat maka penulis memberikan saran untuk pengembangan aplikasi ini kedepannya. Aplikasi ini dapat di kembangkan dengan mengubah tampilan menjadi lebih menarik, menambah jenis game yang ada di aplikasi, membuat soal pada game tebak gambar dapat muncul secara acak setiap kali mengulang permainan, serta kedepannya dapat dikembangkan menjadi berbasis mobile agar lebih mudah untuk dimainkan.

\section{DAFTAR PUSTAKA}

Arsyad, M.A, P. (2009). Media Pembelajaran. Jakarta: Raja Grafindo Persada.

Dewi, G. P. (2012). Pengembangan Game Edukasi Pengenalan Hewan dalam Bahasa Inggris sebagai Media Pembelajaran Siswa SD berbasis Macromedia Flash.

Enjelina, S. (2016). Jurnal Aplikasi Berbasis Web.

Heinich, \& Molenda. (2005). Instructional Technology and Media for Learning. New Jersey: Ohio: Pearson Merrill Prentice Hall.

Novita, D. R. (2010). Pembangunan Media Pembelajaran Bahasa Inggris untuk Siswa Kelas 1 pada Sekolah Dasar Negeri 15 sragen.

Sadiman, A. (2009). Media Pendidikan, Pengertian, Pengembangan, dan Pemanfaatannya. Jakarta: Rajawali Press.

Setyawan, D. (2015). Mengenal Huruf Abjad A-Z.

Sudiatmika, I. A., Cahyawan, A. A., \& Buana, P. W. (2014). Aplikasi Game Edukasi Trash Grabber untuk Mengenal Jenis-Jenis Sampah Pada Smartphone Berbasis Android.

Vaughan, T. (2004). Multimedia : Making It Work. Yogyakarta: Tim Andi Penerbit.Arsyad, M.A, P. (2009). Media Pembelajaran. Jakarta: Raja Grafindo Persada. 